\title{
Parkinson's Disease as Risk Factor in Osteoporosis and Osteoporotic Vertebral Fracture : Prevalence Study Using National Inpatient Sample Database in Korea
}

\author{
Jin Yong Lee, M.D., Ph.D., ${ }^{1,2}$ Nam Gu Lim, Ph.D., ${ }^{3}$ Chun Kee Chung, M.D., Ph.D., ${ }^{4-6}$ Jee-Young Lee, M.D., Ph.D., \\ Hyun Joo Kim R.N., Ph.D., ${ }^{8}$ Sung Bae Park, M.D., Ph.D. ${ }^{9}$ \\ Public Health Medical Service," Boramae Medical Center, Seoul National University College of Medicine, Seoul, Korea \\ Institute of Health Policy and Management, ${ }^{2}$ Medical Research Center, Seoul National University, Seoul, Korea \\ Department of Medical Administration and Information, ${ }^{3}$ Daejeon Health Institute of Technology, Daejeon, Korea \\ Department of Neurosurgery, ${ }^{4}$ Seoul National University College of Medicine, Seoul, Korea \\ Department of Brain and Cognitive Sciences, ${ }^{5}$ Seoul National University College of Natural Sciences, Seoul, Korea \\ Clinical Research Institute, 6 Seoul National University Hospital, Seoul, Korea \\ Department of Neurology, ${ }^{7}$ Seoul National University Boramae Medical Center, Seoul, Korea \\ Department of Nursing Science, ${ }^{8}$ Shinsung University, Dangjin, Korea \\ Department of Neurosurgery, Seoul National University Boramae Medical Center, Seoul, Korea
}

Objective : To determine the prevalence of osteoporosis (OP) and osteoporotic vertebral fracture (OVF) in people with Parkinson's disease (PD) in Korea and its association with socioeconomic status.

Methods : Using Health Insurance Review and Assessment Service-National Inpatient Sample (HIRA-NIS) data from 2009 to 2013, we estimated the annual prevalence of $\mathrm{PD}, \mathrm{OP}$, and OVF and investigated its association with socioeconomic status using data from National Health Insurance (NHI) beneficiaries and Medical Aid (MA) recipients. This study was supported by research funding from Korean Society for Bone and Mineral Research 2015. There were no study-specific biases related to conflicts of interest.

Results : The number of PD patients in the HIRA-NIS increased each year from 2009 to 2013. Among patients with PD, the standardized prevalence rates of OP and OVF increased from 2009 to 2013; from 23.2 to 27.8 and from 2.8 to 4.2 , respectively. Among patients with PD with OP, the prevalence of OVF were 12.2\% and 15.1\% in 2009 and 2013, respectively. The standardized prevalence rates of $\mathrm{PD}$ with $\mathrm{OP}$ and $\mathrm{PD}$ with OVF were significantly higher in MA recipients than in NHI beneficiaries.

Conclusion : The prevalence of PD both with OP and with OVF increased and the prevalence was higher in MA recipients than in $\mathrm{NHI}$ beneficiaries. These findings may suggest that age over 65 years, female and low income may be a significant factor related to PD occurring with OP and OVF.

Key Words : Parkinson disease · Osteoporosis · Fractures, Bone.

\footnotetext{
- Received : January 19, 2018 •Revised : March 10, 2018 •Accepted : April 17, 2018

- Address for reprints : Sung Bae Park, M.D., Ph.D.

Department of Neurosurgery, Seoul National University Boramae Medical Center, 20 Boramae-ro 5-gil, Dongjak-gu, Seoul 07061, Korea Tel : +82-2-870-3301, Fax : +82-2-831-2826, E-mail : ddolbae01@naver.com
}

This is an Open Access article distributed under the terms of the Creative Commons Attribution Non-Commercial License (http://creativecommons.org/licenses/by-nc/4.0) which permits unrestricted non-commercial use, distribution, and reproduction in any medium, provided the original work is properly cited. 


\section{INTRODUCTION}

Parkinson's disease (PD) is a common neurodegenerative disorder in the elderly population ${ }^{6}$. The prevalence of PD in industrialized countries is estimated at about $0.3 \%$ of the entire population and $1-1.5 \%$ of people aged over 60 years ${ }^{23,30,33}$. The cardinal features of PD are tremor at rest, rigidity, bradykinesia, and postural instability, and patients in the advanced stages of PD have reduced mobility and poor feeding ${ }^{11}$. These symptoms are considered to be the main risk factors of reduced bone mass and associated conditions such as osteoporosis (OP) or osteopenia, falls, and fractures, including osteoporotic hip and osteoporotic vertebral fracture $(\mathrm{OVF})^{11,26,31}$. PD may be a strong contributor to both osteoporosis and fracture risk. Therefore, the study about correlation between $\mathrm{PD}$ and osteoporosis may provide a valuable information to $\mathrm{PD}$ and clinician.

$\mathrm{PD}$ affects the overall quality of life (QOL) and may be related to lower socioeconomic status ${ }^{8-10,18,25,34)}$. OP is a worldwide disease, and its prevalence continues to increase in the elderly population, who experience high rates of fragility-related fractures including $\mathrm{OVF}^{24,27}$. OVF can lead to disability, low QOL, and mortality ${ }^{8}$. OP and fragility-related fractures have a serious effect on people's health and QOL because of the resultant chronic pain, morbidity (long-term disability), and mortality ${ }^{4,5,13,17,21,22,28)}$.

The risk of vertebral fragility fractures such as OVF is strongly related to low socioeconomic status ${ }^{24)}$. Patients with PD frequently have OP and experience fragility fracture ${ }^{11,26,311}$. PD patients with OVF may have worse QOL than those without OVF. In addition, low QOL may increase a patient's socioeconomic burden. The size of the elderly population has been increasing annually, and a higher proportion of the elderly population has $\mathrm{PD}, \mathrm{OP}$, or OVF compared with their younger counterparts ${ }^{2,6,24)}$. Given the increase in the number of elderly people, the number of patients with PD and OVF is also expected to increase annually. Therefore, to establish effective prevention strategies, it is important to know the prevalence of comorbid PD and OP and whether PD with OVF is associated with socioeconomic status. Several articles have reported on the relationship between PD, socioeconomic status, and fragility fracture ${ }^{9,18,25,31)}$. However, no studies have used national big data to examine the prevalence and socioeconomic burden of PD with OVF.
We conducted this study to determine the prevalence of PD and PD with OP or OVF, and to investigate whether PD with $\mathrm{OP}$ or OVF is related to socioeconomic status.

\section{MATERIALS AND METHODS}

Fig. 1 showed the framework of this study and the process of calculating the prevalence of PD, PD with OP, and PD with OVF.

\section{Study design and data sources}

This study was designed as a multi-year cross sectional study using the National Inpatient Sample (NIS) database from 2009 to 2013, one of the National Patient Sample databases, which are presented annually by the Health Insurance Review and Assessment Service (HIRA) in Korea. The HIRANIS contains about 700000 inpatients per year (13\% of all inpatients) and about 400000 outpatients per year (1\% of all outpatients) ${ }^{12,14,15)}$. The HIRA-NIS also contains weighted score in each patient therefore can convert the whole Korean populations. For example, if we calculated the 5458 patients with PD using HIRA-NIS 2009, this number can convert 82599 Korean populations.

\section{Setting and source population}

Korea has adopted a Universal Healthcare System in which all Korean citizens must be the National Health Insurance (NHI) beneficiaries or Medical Aids (MA) recipients. Members of low-income families are eligible for MA recipients. The MA system is similar to Medicaid in the USA and is funded by taxes. As of 2014, among the entire Korean population (about 51.7 million people), NHI beneficiaries was 97.1\% (50.3 million) and MA was $2.9 \%$ (1.4 million $)^{20)}$. We have previously reported on the relationship between OVF and socioeconomic status, the Korean medical system, and the representative value of MA among those with low socioeconomic status ${ }^{24)}$. We hypothesize that socioeconomic status can affect the prevalence of Parkinson's disease occurring with osteoporosis and osteoporotic vertebral fracture. In order to prove this hypothesis, we classified the inpatients and outpatients in the HIRANIS database into two groups according to type of insurance : $\mathrm{NHI}$ beneficiaries and MA recipients. 


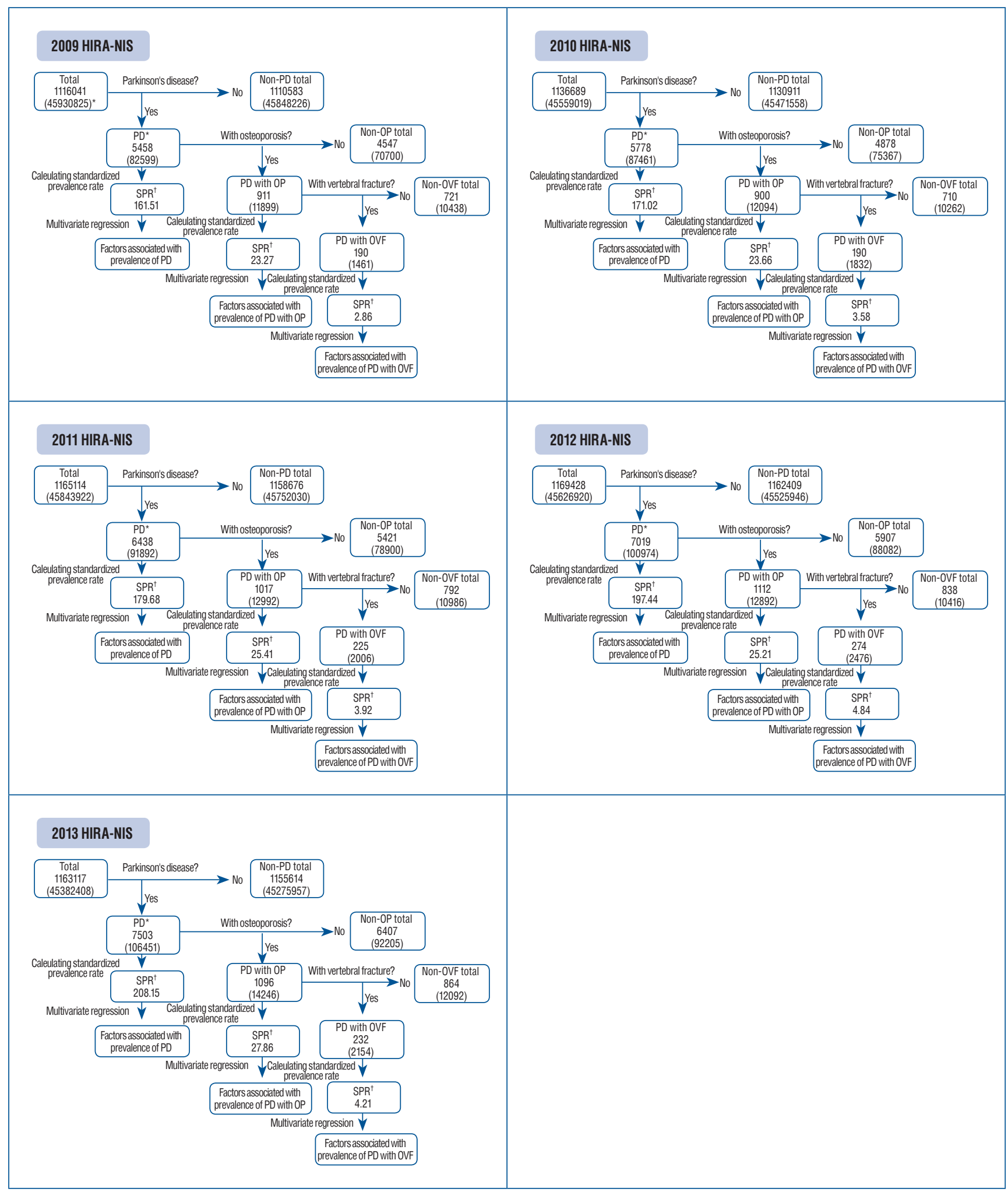

Fig. 1. Framework of this study. ${ }^{*}$ The number of parentheses mean the setimate numbers to the Korean populations. ${ }^{\dagger}$ Per 100000 Korean people. HIRANIS : Health Insurance Review and Assessment Service-National Inpatient Sample, PD : Parkinson's disease, OP : osteoporosis, SPR : standardized prevalence rate, OVF : osteoporotic vertebral fracture. 


\section{Participants}

PD patients

Patients were considered to have PD if they were diagnosed as having PD according to the G20 code in the HIRA-NIS database from 2009 to 2013, which is based on the International Classification of Diseases, 10th Revision (ICD-10). In clinical field of Korea, majority of PD patients were assigned to G20 code. In addition, the number of the patients registered as secondary PD was too small to get statistical significance. Because of that, we analyzed the group of the PD patients with G20 code in the present study.

\section{PD patient with OP}

Among the patients with PD, we selected patients with OP. Patients with OP were defined as those having fulfilled at least one of the following ICD-10 diagnosis codes : M810 (postmenopausal osteoporosis), M818 (senile osteoporosis), M819 (male osteoporosis), M800 (postmenopausal osteoporosis with pathologic fracture), M808 (osteoporotic compression fracture), or M809 (osteoporosis with pathologic fracture).

\section{PD patient with OVF}

Among the patients with PD, we defined patients with OVF as those fulfilling one of the following two criteria. The first was a diagnosis of at least one of the ICD-10 codes M800, M808, or M809, and the second was a diagnosis of at least one of the ICD-10 codes M810, M818, or M819, together with a diagnosis of at least one of the ICD-10 codes S220 (fracture of thoracic spine), S221 (multiple fracture of thoracic spine), or S32 (fracture of lumbar spine) at the same time.

\section{Measurement}

In this study, prevalence refers to the total number of cases of PD, PD with OP, or PD with OVF, in a whole Korean population estimated from the HIRA-NIS database at years of 2009, 2010, 2011, 2012 and 2013, respectively. That is, we adopted the concept of period prevalence (usually the past 12 months, 1 year) which is more applicable to the HIRA-NIS database $^{24)}$. We calculated prevalence in two ways : crude prevalence and standardized prevalence rate (SPR). Crude prevalence means the actual number and calculates without any adjustment, and SPR refers adjusted number after reflecting population structure such as sex and age. To calculate the
SPR, prevalence was adjusted by sex and age using 2013 population data from the Korea National Statistics Office and then calculated as an annual number per 100000 population.

\section{Statistical methods}

\section{Covariates}

To investigate whether the prevalence of the conditions of interest is associated with socioeconomic status, we defined the following as covariates: age (under 65 years vs. 65 years and older), sex (male vs. female), type of medical center where the patient was treated (tertiary hospital, general hospital, hospital, and clinic), region (metropolitan areas vs. nonmetropolitan areas), and the Charlson comorbidity index (CCI), which is a summary score index that includes 17 medical conditions to quantify the severity of disease ${ }^{12,35)}$. In this study, we categorized CCI scores into three ranges : $0,1-2$, and 3 and higher more than 3 .

\section{Frequence analysis and multivariate logistic regression}

Frequency analyses were performed to examine the distributions of the prevalence of PD, PD with OP, and PD with OVF from 2009 to 2013 . To identify those factors related to the prevalence of PD, PD with OP, and PD with OVF, we conducted multivariate analyses using the logistic regression method. All analyses were performed using SPSS version 20 (IBM Corporation, Armonk, NY, USA). All statistical tests were two-sided, and a $p$-value $<0.05$ was considered significant.

\section{Ethical approval}

This study was exempted from approval by the Institutional Review Board of Seoul National University Boramae Hosptial (IRB No. 07-2015-14/102) because it was dealt with anonymous patient health records presented by HIRA. Therefore, we could not find the study participants and there were no need informed consents of patients in the present study.

\section{RESULTS}

Because the present study used the registered national big data, there was no missing data. Fig. 1 showed the flow of analysis and summarized results. 


\section{Main results}

\section{Prevalence of PD}

In the HIRA-NIS database, the number of people with PD increased each year from 2009 to 2013 (82599, 87461, 91891,
100974, and 106451, respectively). The SPRs of PD were estimated as 161, 171, 179, 197, and 208 per 100000 population, respectively. Around $89 \%$ of patients with PD were older than 60 years, and the 70s was the peak age range for the prevalence of PD. The crude prevalence rate and SPR of PD were higher

Table 1. Prevalence of Parkinson's disease along with OP in Korean population between 2009 and 2013

\begin{tabular}{|c|c|c|c|c|c|c|c|c|c|c|}
\hline \multirow{2}{*}{ Variable } & \multicolumn{2}{|l|}{2009} & \multicolumn{2}{|l|}{2010} & \multicolumn{2}{|l|}{2011} & \multicolumn{2}{|l|}{2012} & \multicolumn{2}{|l|}{2013} \\
\hline & $N$ & $S P R^{*}$ & $N$ & $\mathrm{SPR}^{*}$ & $N$ & $S P R^{*}$ & $N$ & SPR* & $N$ & $S P R^{*}$ \\
\hline Total & $82599(100.0)$ & 161.51 & $87461(100.0)$ & 171.02 & 91892 (100.0) & 179.68 & $100974(100.0)$ & 197.44 & $106451(100.0)$ & 208.15 \\
\hline$O P^{*}$ & 11899 (14.4) & 23.27 & 12094 (13.8) & 23.65 & 12992 (14.1) & 25.41 & $12892(12.8)$ & 25.21 & $14246(13.4)$ & 27.86 \\
\hline Non-OP* & 70700 (85.6) & 138.24 & $75367(86.2)$ & 147.37 & $78900(85.9)$ & 154.28 & 88082 (87.2) & 172.23 & 92205 (86.6) & 180.29 \\
\hline \multicolumn{11}{|l|}{ Age (years) } \\
\hline$\leq 19$ & 0 & 0 & 0 & 0 & 0 & 0 & 0 & 0 & 0 & 0 \\
\hline $20-29$ & $8(0.1)$ & 0.12 & 0 & 0 & 0 & 0 & 0 & 0 & 0 & 0 \\
\hline $30-39$ & 0 & 0 & 0 & 0 & 0 & 0 & $8(0.1)$ & 0.1 & 0 & 0 \\
\hline $40-49$ & $238(2.0)$ & 2.67 & $8(0.1)$ & 0.09 & $16(0.1)$ & 0.18 & $16(0.1)$ & 0.18 & $23(0.2)$ & 0.26 \\
\hline $50-59$ & $115(1.0)$ & 1.43 & $377(3.1)$ & 4.7 & $623(4.8)$ & 7.76 & $577(4.5)$ & 7.19 & $238(1.7)$ & 2.97 \\
\hline $60-69$ & 2646 (22.2) & 59.16 & 2885 (23.9) & 14.26 & $2747(21.1)$ & 61.42 & $2638(20.5)$ & 58.98 & $2584(18.1)$ & 57.77 \\
\hline $70-79$ & $6546(55.0)$ & 213.03 & 6708 (55.5) & 66.87 & 7501 (57.7) & 244.11 & $6831(53.0)$ & 222.31 & 7715 (54.2) & 251.07 \\
\hline$\geq 80$ & $2346(19.7)$ & 196.76 & $2116(17.5)$ & 93.37 & 2108 (16.2) & 176.8 & $2823(21.9)$ & 236.77 & 3685 (25.9) & 309.07 \\
\hline \multicolumn{11}{|l|}{ Gender } \\
\hline Male & 1415 (11.9) & 5.53 & 1631 (13.5) & 6.37 & 1416 (10.9) & 5.53 & $1516(11.8)$ & 5.92 & $1185(8.3)$ & 4.63 \\
\hline Female & $10484(88.1)$ & 41.03 & $10463(86.5)$ & 40.95 & 11579 (89.1) & 45.31 & 11377 (88.2) & 44.52 & 13060 (91.7) & 51.11 \\
\hline \multicolumn{11}{|l|}{ Type of insurance } \\
\hline Health insurance & $9638(81.0)$ & 19.4 & $9870(81.6)$ & 19.86 & 11485 (88.4) & 23.11 & $11362(88.1)$ & 22.87 & $11969(84.0)$ & 24.09 \\
\hline Medical aid & 2261 (19.0) & 155.91 & $2223(18.4)$ & 153.29 & 1508 (11.6) & 103.99 & 1531 (11.9) & 105.57 & $2277(16.0)$ & 157.02 \\
\hline \multicolumn{11}{|l|}{ Type of medical center } \\
\hline $\begin{array}{l}\text { Tertiary teaching } \\
\text { hospital }\end{array}$ & $6330(53.2)$ & & $5900(48.8)$ & & 6615 (50.9) & & 4392 (34.1) & & $5115(35.9)$ & \\
\hline General hospital & $4269(35.9)$ & & 4754 (39.3) & & $5069(39.0)$ & & $6992(54.2)$ & & $7723(54.2)$ & \\
\hline Hospital & $724(6.1)$ & & $1100(9.1)$ & & $985(7.6)$ & & $1269(9.8)$ & & $1139(8.0)$ & \\
\hline Clinic & $577(4.8)$ & & $339(2.8)$ & & $323(2.5)$ & & $238(1.8)$ & & $270(1.9)$ & \\
\hline \multicolumn{11}{|l|}{ Region } \\
\hline Metropolitan & 7977 (67.0) & 34.36 & 8961 (74.1) & 38.6 & 9477 (72.9) & 40.82 & 8700 (67.5) & 37.48 & $9684(68.0)$ & 41.71 \\
\hline Non-metropolitan & $3923(33.0)$ & 14.05 & $3130(25.9)$ & 11.21 & $3515(27.1)$ & 12.59 & $4192(32.5)$ & 15.01 & $4561(32.0)$ & 16.33 \\
\hline \multicolumn{11}{|l|}{$\begin{array}{l}\text { Charlson comorbidity } \\
\text { index }\end{array}$} \\
\hline 0 & 1585 (13.3) & & 2485 (20.5) & & $2923(22.5)$ & & 3107 (24.1) & & $3492(24.5)$ & \\
\hline $1-2$ & $5770(48.5)$ & & $6416(53.1)$ & & $7815(60.2)$ & & $7438(57.7)$ & & $8092(56.8)$ & \\
\hline$\geq 3$ & 4546 (38.2) & & $3192(26.4)$ & & $2253(17.3)$ & & 2346 (18.2) & & $2662(18.7)$ & \\
\hline
\end{tabular}

Values are presented as number (\%). *Per 100000 Korean people. OP : osteoporosis, SPR : standardized prevalence rate 


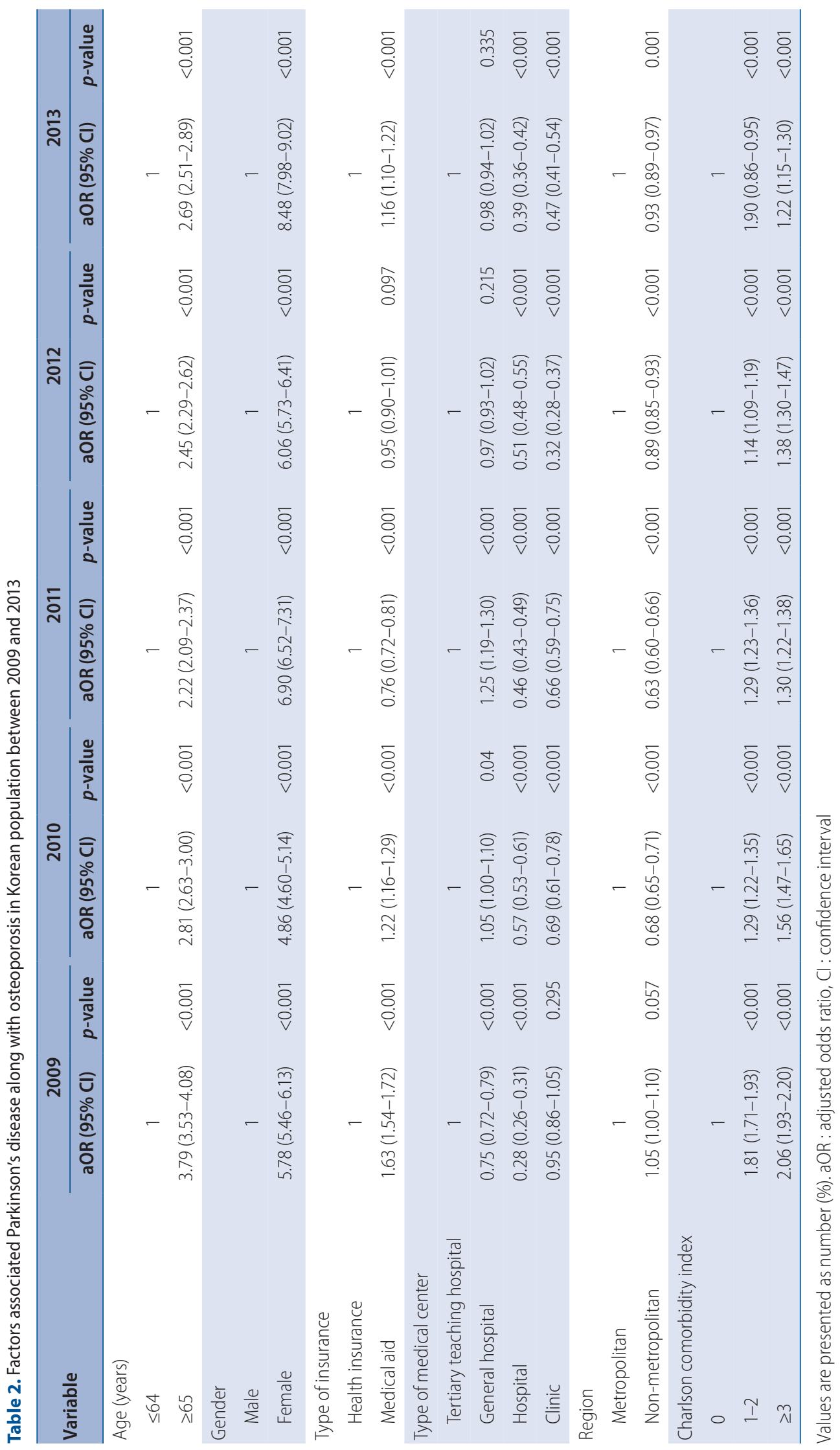


Parkinson in Osteoporosis | Lee JY, et al.

Table 3. Prevalence of osteoporotic vertebral fracture in Parkinson's disease in Korean population between 2009 and 2013

\begin{tabular}{|c|c|c|c|c|c|c|c|c|c|c|}
\hline \multirow{2}{*}{ Variable } & \multicolumn{2}{|l|}{2009} & \multicolumn{2}{|l|}{2010} & \multicolumn{2}{|l|}{2011} & \multicolumn{2}{|l|}{2012} & \multicolumn{2}{|l|}{2013} \\
\hline & $\mathrm{N}$ & $\mathrm{SPR}^{*}$ & $\mathrm{~N}$ & $\mathrm{SPR}^{*}$ & $\mathrm{~N}$ & $\mathrm{SPR}^{*}$ & $\mathrm{~N}$ & $\mathrm{SPR}^{*}$ & $\mathrm{~N}$ & $\mathrm{SPR}^{*}$ \\
\hline Total & $11899(100.0)$ & 23.27 & 12094 (100.0) & 23.65 & $12992(100.0)$ & 25.41 & $12892(100.0)$ & 25.21 & $14246(100.0)$ & 27.86 \\
\hline$O P^{*}$ & $1461(12.3)$ & 2.86 & $1832(15.1)$ & 3.58 & $2006(15.5)$ & 3.92 & 2476 (19.2) & 4.84 & 2154 (15.1) & 4.21 \\
\hline Non-OP* & 10438 (87.7) & 20.41 & $10262(84.9)$ & 20.07 & $10986(84.5)$ & 21.48 & $10416(80.8)$ & 20.37 & $12092(84.9)$ & 23.64 \\
\hline \multicolumn{11}{|l|}{ Age (years) } \\
\hline$\leq 19$ & 0 & 0 & 0 & 0 & 0 & 0 & 0 & 0 & 0 & 0 \\
\hline $20-29$ & 0 & 0 & 0 & 0 & 0 & 0 & 0 & 0 & 0 & 0 \\
\hline $30-39$ & 0 & 0 & 0 & 0 & 0 & 0 & 0 & 0 & 0 & 0 \\
\hline $40-49$ & 0 & 0 & 0 & 0 & 0 & 0 & 0 & 0 & 0 & 0 \\
\hline $50-59$ & 0 & 0 & $16(0.9)$ & 0.2 & $15(0.7)$ & 0.19 & $38(1.5)$ & 0.47 & 0 & 0 \\
\hline $60-69$ & $261(17.9)$ & 5.84 & $223(12.2)$ & 4.99 & $400(19.9)$ & 8.94 & $369(14.9)$ & 8.25 & $200(9.3)$ & 4.47 \\
\hline $70-79$ & $854(58.5)$ & 27.79 & $1216(66.4)$ & 39.57 & $1230(61.3)$ & 40.03 & $1400(56.5)$ & 45.56 & $1423(66.1)$ & 46.31 \\
\hline$\geq 80$ & $346(23.7)$ & 29.02 & $377(20.6)$ & 31.62 & $361(18.0)$ & 30.28 & $669(27.0)$ & 56.11 & $531(24.7)$ & 44.54 \\
\hline \multicolumn{11}{|l|}{ Gender } \\
\hline Male & $200(13.7)$ & 0.78 & $231(12.6)$ & 0.9 & $253(12.6)$ & 0.99 & $223(9.0)$ & 0.87 & $231(10.7)$ & 0.9 \\
\hline Female & 1261 (86.3) & 4.93 & $1601(87.4)$ & 6.27 & $1753(87.4)$ & 6.86 & $2253(91.0)$ & 8.82 & 1923 (89.3) & 7.53 \\
\hline \multicolumn{11}{|l|}{ Type of insurance } \\
\hline Health insurance & $1247(85.3)$ & 2.51 & $1277(69.8)$ & 2.57 & $1753(87.4)$ & 3.53 & $2215(89.4)$ & 4.46 & $1731(80.4)$ & 3.48 \\
\hline Medical aid & $215(14.7)$ & 14.83 & $553(30.2)$ & 38.13 & $253(12.6)$ & 17.45 & $262(10.6)$ & 18.07 & 423 (19.6) & 29.17 \\
\hline \multicolumn{11}{|l|}{ Type of medical center } \\
\hline $\begin{array}{l}\text { Tertiary teaching } \\
\text { hospital }\end{array}$ & $746(51.1)$ & & $592(32.3)$ & & $1061(52.8)$ & & $738(29.8)$ & & $593(27.5)$ & \\
\hline General hospital & $615(42.1)$ & & $1100(60.1)$ & & $647(32.2)$ & & 1538 (62.1) & & 1415 (65.7) & \\
\hline Hospital & $100(6.8)$ & & $123(6.7)$ & & $292(14.5)$ & & $192(7.8)$ & & $146(6.8)$ & \\
\hline Clinic & 0 & & $15(0.8)$ & & $8(0.4)$ & & $8(0.3)$ & & 0 & \\
\hline \multicolumn{11}{|l|}{ Region } \\
\hline Metropolitan & $1038(71.0)$ & 4.47 & $1169(63.8)$ & 5.04 & $1500(74.7)$ & 6.46 & $1646(66.5)$ & 7.09 & $1646(76.4)$ & 7.09 \\
\hline Non-metropolitan & $423(29.0)$ & 1.51 & $662(36.2)$ & 2.37 & $507(25.3)$ & 1.82 & 831 (33.5) & 2.98 & $508(23.6)$ & 1.82 \\
\hline \multicolumn{11}{|l|}{$\begin{array}{l}\text { Charlson comorbidity } \\
\text { index }\end{array}$} \\
\hline 0 & $207(14.2)$ & & $369(20.2)$ & & $500(24.9)$ & & $453(18.3)$ & & $385(17.9)$ & \\
\hline $1-2$ & $708(48.5)$ & & $992(54.2)$ & & $1154(57.5)$ & & $1631(65.9)$ & & $1300(60.4)$ & \\
\hline$\geq 3$ & $546(37.4)$ & & $470(25.7)$ & & 354 (17.6) & & $392(15.8)$ & & $469(21.8)$ & \\
\hline
\end{tabular}

Values are presented as number (\%). *Per 100000 Korean people. SPR : standardized prevalence rate, OP : osteoporosis

in women than in men. More than $80 \%$ of patients with PD were treated in a tertiary teaching hospital or general hospital. More than two-thirds of patients with PD lived in a metropolitan area. Forty-three to $58 \%$ of patients with PD had at least one comorbid disease and a CCI score of 1 or 2 .

\section{Prevalence of $\mathrm{PD}$ with $\mathrm{OP}$}

As of 2009, the change from 2009 to 2013 of prevalence of PD with OP was $12.8 \%$ to $14.4 \%$, regardless of sex or age. More than $95 \%$ of patients with PD with OP were older than 60 years, and more women than men had PD with OP. As observed for PD, more than two-thirds of patients with PD with 


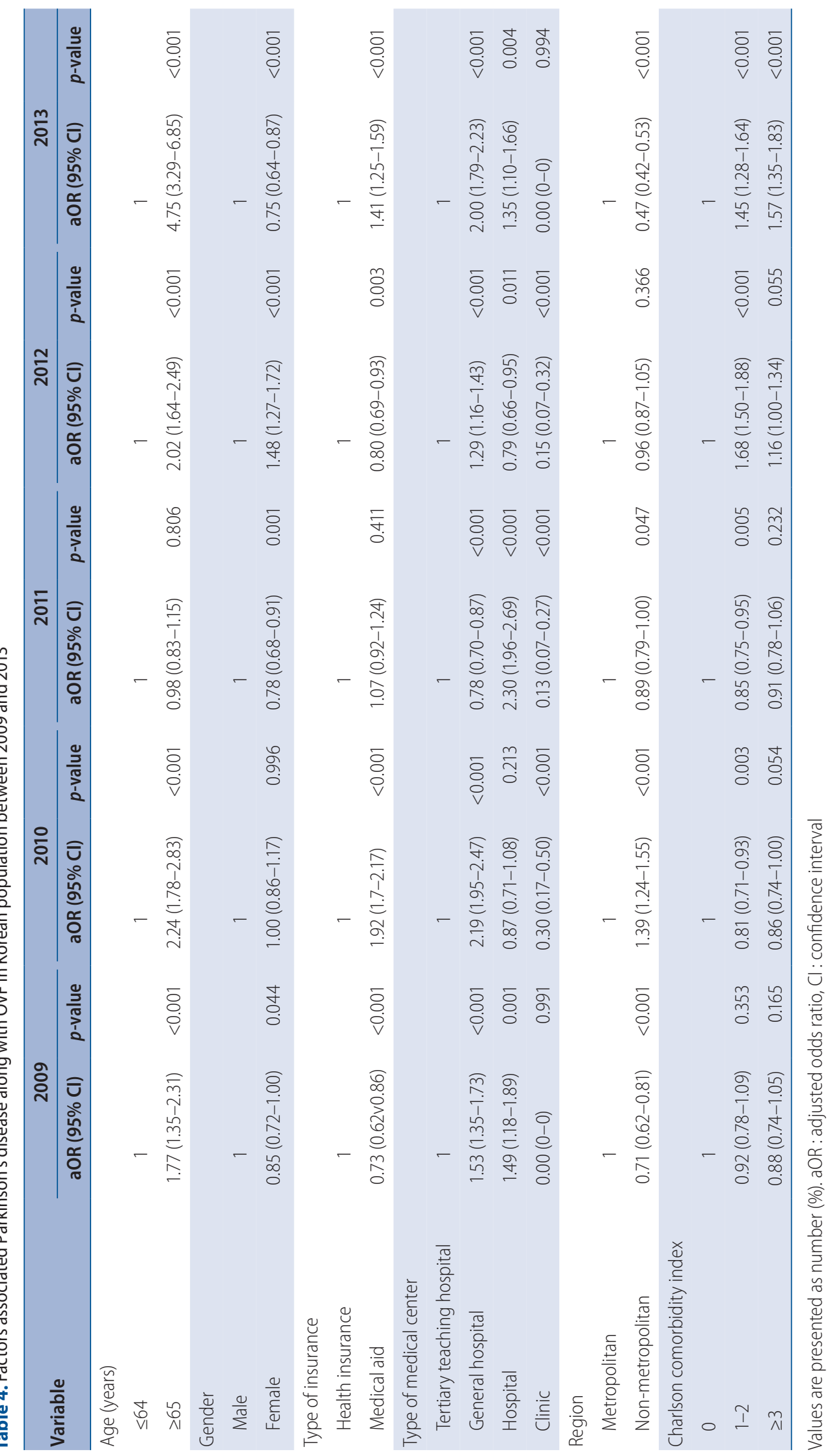


OP lived in a metropolitan area and visited a tertiary teaching hospital or general hospital for treatment. The SPRs for PD with OP were significantly higher in the MA recipients than in NHI beneficiaries from 2009 to 2013 (Table 1). PD patients older than 64 years, females, and MA recipients had a higher risk of also having OP, and PD with OP was significantly related to receiving MA except 2011 data. In addition, all people with PD with OP lived mostly in metropolitan and visited tertiary teaching or general hospitals (Table 2).

\section{Prevalence of PD with OVF}

Among PD patients with OP, the number with OVF increased from 2009 to 2013 (1461, 1832, 2006, 2476, and 2145, respectively). SPRs also increased during this time $(23,23,25$, 25, and 27 per 100000 population, respectively). More than $80 \%$ of the patients were older than 70 years, and $>86 \%$ were women. Most PD patients with OVF (82-91\%) were treated in a tertiary teaching or general hospital. More than $66 \%$ of patients with PD with OVF lived in a metropolitan area, and 48.5-65.9\% of patients with PD with OVF had another comorbidity with a CCI score of 1 or 2 . In a comparison analysis of SPRs for the NHI and MA groups, the prevalence of PD with OVF was significantly higher in MA recipients than in NHI beneficiaries from 2009 to 2013 (Table 3). However, the factor related to OVF among PD patients was the patients older than 65 years. The female and MA were not always significant factors related to OVF among PD patients (Table 4).

\section{DISCUSSION}

In the present study, the prevalence rates of $\mathrm{PD}, \mathrm{PD}$ with OP, and PD with OVF were significantly higher in MA recipients than in NHI beneficiaries. Because no previous study has used big data to examine PD with OVF in Korea, we believe that our study provides more accurate information about the SPRs of PD with OVF and the relationship between PD with OVF and low socioeconomic status.

The present study did have several limitations. First, although medical records were analyzed from a database that included around 1100000 people, stratified random sample data may not be representative of the entire population of Korea. We plan further studies to analyze the entire Korean population database using the HIRA. Second, patients with as- ymptomatic OVF in Korea may not seek medical care, and the prevalence of OVF in patents with PD might have been underestimated in our study. Because the stratified random sample data were collected without consideration of the ratio between people covered by the MA and NHI, the present study had insufficient statistical power to recommend the relationship of PD with OVF and socioeconomic status here using the gap of socioeconomic status between MA and NHI. Therefore, future research should include the entire population and specific socioeconomic status groupings such as very poor families, poor families, and everyone else. Third, we did not examine the risk factors for PD with OVF among MA recipients, and we focused only on the prevalence of OVF and related general factors in PD patients. Therefore, future studies are also needed to identify the risk factors associated with low socioeconomic status as a basis for developing strategies to prevent OVF in patents with $\mathrm{PD}$.

PD can impair an individual's QOL and place a large burden on the health care system, especially in low-income areas $^{9,10,18,25)}$. We found that the crude and SPR prevalence rates of OP and OVF were higher in MA recipients than in NHI beneficiaries ${ }^{24)}$. Musculoskeletal problems are more common in PD patients, and OP and fractures are significantly more prevalent in past diagnoses associated with musculoskeletal problems in people with $\mathrm{PD}^{16)}$. In our previous study, we reported the prevalence rates of OP and OVF for the whole population in Korea as around $4 \%$ and $0.5 \%$, respectively ${ }^{24}$. In the present study, the prevalence rates of PD with OP and PD with OVF were around $14 \%$ and $1.8 \%$, respectively. Because PD is a progressive disease, the prevalence of PD-related bone problems increases with age, and PD currently affects an estimated $1 \%$ of people aged $>60$ years ${ }^{19)}$. In the present study, the prevalence rates of PD with OP and PD with OVF increased with age. Although more than $80 \%$ of PD patients were older than 70 years in our study, the 70 s was the peak age range for the prevalence of PD, PD with OP, and PD with OVF. The 70s has also been reported to be the most common age range for $\mathrm{PD}$ and PD with OVF in other studies ${ }^{24)}$. The neuroprotective effects of estrogens have been suggested as a possible explanation for the difference in prevalence between men and women, but this explanation remains controversial. Some studies have reported a higher prevalence of PD in men than in wom$\mathrm{en}^{1,3,29)}$, whereas other studies have presented a difference in PD prevalence between men and women ${ }^{7,32)}$. In our study, the 
prevalence rates of $\mathrm{PD}, \mathrm{PD}$ with $\mathrm{OP}$, and $\mathrm{PD}$ OVF were higher in women. This suggests that other factors, such as culture and the social environment, may determine whether the prevalence of PD differs between men and women.

In the present study, more than $70 \%$ of patients with $\mathrm{PD}$, PD with OP, or PD with OVF lived in a metropolitan area and were treated in a tertiary teaching or general hospital. Because PD is a progressive disease and has many other comorbid diseases such as musculoskeletal problems, patients with PD in Korea are usually treated in a general hospital. Patients with PD symptoms who live in nonmetropolitan areas in Korea may be less likely to receive a proper diagnosis of or care for PD compared with those living in metropolitan areas. Further studies using big data of the whole population and cohort studies of populations in nonmetropolitan areas are needed.

The prevalence rates of OP and OVF were higher in PD patients than in the whole population, as determined using HIRANIS data in Korea. We also found that PD, PD with OP, and PD with OVF were strongly related to low socioeconomic status. These results suggest that patients with PD should be provided with preventive medical care to avoid or treat OP because PD is a high-risk disease for OVF. This is especially true for MA recipients, among whom early identification of the risk of OVF and preventive or therapeutic intervention for OP may help reduce the prevalence of OP and the incidence of OVF.

The data set in the current study is NIS database provided from HIRA in Korea. HIRA provided the NIS dataset from 2009 to 2013 when the authors started to analyze the NIS database in 2016. Now, the HIRA is releasing NIS database up to 2015 with charging a fee for use. We will analyze the updated database in our future studies. This study was the cross-sectional multiyear study for estimating prevalence of $\mathrm{PD}, \mathrm{PD}$ with OP, and PD with OVF and emphasizing the risk of OVF in PD patients. Because of that, we could not show the results related with incidence. On the analysis of the NIS dataset in the present study, it was impossible to distinguish the people with or without the medication for OP due to the limitation of the dataset contents. However, the prevalence of OP in the whole population and patients with PD were $4 \%$ and $14 \%$, respectively in the previous ${ }^{24)}$ and present studies. Also, the prevalence of OVF in the whole population and patients with PD were $0.5 \%$ and $1.8 \%$, respectively, in the same studies. Because the prevalence of PD and OP and OVF are both increasing with age, it is difficult to tell accurate contribution of OP and OVF in aged PD population compared to those in general aged population with our prevalence data. The authors did not analyze incidence data. However, in the present study, the authors aimed to determine the prevalence of PD and PD with OP or OVF, and to investigate whether PD with OP or OVF is related to socioeconomic status. The new dataset will be needed to find factors related with the difference between general aged people with OP and OVF and aged PD with OP and OVF. The authors will analyze another database to find the cause attributable to OP and OVF of PD patients in future study. In addition to, authors did not know whether the patients were referred to the endocrine doctor prior to the onset of PD of after development of PD due to the limitation of characteristics of NIS database provided by national institute (HIRA). In addition, there may be some limitations to prove the causal relationship just using observation data. Therefore, we need the experimental study or another approach style in analyzing observation study as Bayesian inference in the future study. Another limitation is that it may be improper to present the socioeconomic effect of PD just using registration of medical aids or not. In the future study, the authors should find the way to reflect the socioeconomic effect of PD than those of medial aids or not.

\section{CONCLUSION}

The prevalence of PD and OVF, and the prevalence rates of PD with OP and PD with OVF increased with age and were higher in women than in men. The prevalence rates of PD or PD with OP or with OVF were significantly higher in MA recipients than in NHI beneficiaries. These findings suggest that low socioeconomic status may be a significant factor related to OP and OVF in people with PD. We believe that these data may be considered when developing health strategies to prevent $\mathrm{OP}$ and OVF in PD patients.

\section{CONFLICTS OF INTEREST}

No potential conflict of interest relevant to this article was reported. 


\section{INFORMED CONSENT}

This type of study does not require informed consent.

\section{- Acknowledgements}

This research was supported by Basic Science Research Program through the National Research Foundation of Korea (NRF) funded by the Ministry of Education (grant number: 2017028643)

\section{References}

1. Benito-León J, Bermejo-Pareja F, Rodríguez J, Molina JA, Gabriel R, Morales JM, et al. : Prevalence of PD and other types of parkinsonism in three elderly populations of central Spain. Mov Disord 18 : 267-274, 2003

2. Caslake R, Taylor K, Scott N, Gordon J, Harris C, Wilde K, et al. : Age-, gender-, and socioeconomic status-specific incidence of Parkinson's disease and parkinsonism in northeast Scotland: the PINE study. Parkinsonism Relat Disord 19 : 515-521, 2013

3. Clavería LE, Duarte J, Sevillano MD, Pérez-Sempere A, Cabezas C, Rodríguez $\mathrm{F}$, et al. : Prevalence of Parkinson's disease in Cantalejo, Spain: a door-to-door survey. Mov Disord 17 : 242-249, 2002

4. Cole ZA, Dennison EM, Cooper C : Osteoporosis epidemiology update. Curr Rheumatol Rep $10:$ 92-96, 2008

5. Cummings SR, Melton LJ : Epidemiology and outcomes of osteoporotic fractures. Lancet 359 : 1761-1767, 2002

6. de Lau LM, Breteler MM : Epidemiology of Parkinson's disease. Lancet Neurol $6: 525-535,2006$

7. de Rijk MC, Breteler MM, Graveland GA, Ott A, Grobbee DE, van der Meché $F G$, et al. : Prevalence of Parkinson's disease in the elderly: the Rotterdam study. Neurology 45 : 2143-2146, 1995

8. Dowding $\mathrm{CH}$, Shenton $\mathrm{CL}$, Salek SS. A review of the health-related quality of life and economic impact of Parkinson's disease. Drugs Aging 23 : 693-721, 2006

9. Findley L, Aujla M, Bain PG, Baker M, Beech C, Bowman C, et al. : Direct economic impact of Parkinson's disease: a research survey in the United Kingdom. Mov Disord 18 : 1139-1145, 2003

10. Guttman M, Slaughter PM, Theriault ME, DeBoer DP, Naylor CD : Parkinsonism in Ontario: physician utilization. Can J Neurol Sci 29 : 221 226, 2002

11. Invernizzi M, Carda S, Viscontini GS, Cisari C : Osteoporosis in Parkinson's disease. Parkinsonism Relat Disord 5 : 339-346, 2009

12. Kim J, Rhee CK, Yoo KH, Kim YS, Lee SW, Park YB, et al. : The health care burden of high grade chronic obstructive pulmonary disease in Korea: analysis of the Korean Health Insurance Review and Assessment Service data. Int J Chron Obstruct Pulmon Dis 8 : 561-568, 2013
13. Kim KH, Lee K, Ko YJ, Kim SJ, Oh SI, Durrance DY, et al. : Prevalence, awareness, and treatment of osteoporosis among Korean women: the Fourth Korea National Health and Nutrition Examination Survey. Bone 50 : 1039-1047, 2012

14. Kim L, Kim JA, Kim S : A guide for the utilization of Health Insurance Review and Assessment Service National Patient Samples. Epidemiol Health 30 : e2014008, 2014

15. Kim L, Sakong J, Kim Y, Kim S, Kim S, Tchoe B, et al. : Developing the inpatient sample for the National Health Insurance claims data. Health Policy Manag 23 : 152-161, 2013

16. Kim YE, Lee WW, Yun JY, Yang HJ, Kim HJ, Jeon BS : Musculoskeletal problems in Parkinson's disease: neglected issues. Parkinsonism Relat Disord 19 : 666-669, 2013

17. Lee YK, Jang S, Jang S, Lee HJ, Park C, Ha YC, et al. : Mortality after vertebral fracture in Korea: analysis of the National Claim Registry. Osteoporos Int 23 : 1859-1865, 2012

18. Lix LM, Hobson DE, Azimaee M, Leslie WD, Burchill C, Hobson S : Socioeconomic variations in the prevalence and incidence of Parkinson's disease: a population-based analysis. J Epidemiol Community Health $64: 335-340,2010$

19. Lyell $V$, Henderson $E$, Devine $M$, Gregson C : Assessment and management of fracture risk in patients with Parkinson's disease. Age Ageing 44 : 34-41, 2015

20. National Health Insurance Service: Annual Report of National Health Insurance Statistics 2014. Available at : http://www.nhis. or.kr/menu/ retriveMenuSet.xx?menuld=F3321

21. Navarro MC, Sosa M, Saavedra P, Lainez P, Marrero M, Torres M, et al. : Poverty is a risk factor for osteoporotic fractures. Osteoporos Int 20 : 393-398, 2009

22. Navarro Mdel C, Saavedra P, Jódar E, Gómez de Tejada MJ, Mirallave A, Sosa M : Osteoporosis and metabolic syndrome according to socioeconomic status, contribution of PTH, vitamin D and body weight: the Canarian Osteoporosis Poverty Study (COPS). Clin Endocrinol (0xf) $78:$ 681-686, 2013

23. Nussbaum RL, Ellis CE : Alzheimer's disease and Parkinson's disease. N Engl J Med 348 : 1356-1364, 2003

24. Park SB, Kim J, Jeong JH, Lee JK, Chin DK, Chung CK, et al. : Prevalence and incidence of osteoporosis and osteoporotic vertebral fracture in Korea: nationwide epidemiological study focusing on differences in socioeconomic status. Spine (Phila Pa 1976) 41 : 328-336, 2016

25. Pressley JC, Louis ED, Tang MX, Cote L, Cohen PD, Glied S, et al. : The impact of comorbid disease and injuries on resource use and expenditures in parkinsonism. Neurology $60: 87-93,2003$

26. Rascol O, Perez-Lloret S, Damier P, Delval A, Derkinderen P, Destée A, et al. : Falls in ambulatory non-demented patients with Parkinson's disease. J Neural Transm (Vienna) 122 : 1447-1455, 2015

27. Reginster JY, Burlet $\mathrm{N}$ : Osteoporosis: a still increasing prevalence. Bone 38 (2 Suppl 1) : S4-S9, 2006

28. Salaffi F, Cimmino MA, Malavolta N, Carotti M, Di Matteo L, Scendoni P, et al. : The burden of prevalent fractures on health-related quality of life in postmenopausal women with osteoporosis: the IMOF study. J Rheu- 
matol 34 : 1551-1560, 2007

29. Saunders-Pullman $\mathrm{R}$ : Estrogens and Parkinson disease: neuroprotective, symptomatic, neither, or both? Endocrine $21:$ 81-87, 2003

30. Seo WK, Koh SB, Kim BJ, Yu SW, Park MH, Park KW, et al. : Prevalence of Parkinson's disease in Korea. J Clin Neurosci 14 : 1155-1157, 2007

31. Tan L, Wang Y, Zhou L, Shi Y, Zhang F, Liu L, et al. : Parkinson's disease and risk of fracture: a meta-analysis of prospective cohort studies. PLoS One 9 : e94379, 2014

32. Tison, F, Dartigues JF, Dubes $L$, Zuber $M$, Alperovitch A, Henry P : Prevalence of Parkinson's disease in the elderly: a population study in Gironde, France. Acta Neurol Scand 90 : 111-115, 1994
33. von Campenhausen S, Bornschein B, Wick R, Bötzel K, Sampaio C, Poewe $W$, et al. : Prevalence and incidence of Parkinson's disease in Europe. Eur Neuropsychopharmacol 15 : 473-490, 2005

34. Winter $Y$, Balzer-Geldsetzer M, Spottke A, Reese JP, Baum E, Klotsche $J$, et al. : Longitudinal study of the socioeconomic burden of Parkinson's disease in Germany. Eur J Neurol 17 : 1156-1163, 2010

35. Woo HK, Park JH, Kang HS, Kim SY, Lee SI, Nam HH : Charlson Comorbidity Index as a predictor of long-term survival after surgery for breast cancer: a nationwide retrospective cohort study in South Korea. J Breast Cancer 13 : 409-417, 2010 